met by the suggestion that dietetic factors tended to protect the liver from attacks of virus or other infections. Were they not dealing with livers which were infected, not protected, and therefore possibly " tilted over", by arsenicals, whereas under peace-time conditions with a properly balanced diet, jaundice was practically an unknown thing?

\title{
THE COMPULSORY TREATMENT OF VENEREAL DISEASES UNDER REGULATION 33B
}

\author{
By N. P. SHANNON, of Gray's Inn, Barrister-at-Law
}

(In the March issue of the Journal we published the first section of this commentary. This second and concluding section deals with the enforcement of the Regulation.)

(6) If a patient found by a special practitioner to be suffering from a venereal disease gives to him information as to a person from whom the patient suspects that the disease was contracted, such information shall be deemed-

(a) for the purposes of paragraph (2) of Regulation 82 of these Regulations, to have been furnished for the purpose of this Regulation;

(b) for the purposes of the law relating to defamation, to have been communicated in pursuance of a statutory duty ;

(c) for the purposes of Regulation 84 of these Regulations, to have been obtained by the practitioner by virtue of this Regulation.

\section{Notes to paragraph (6)}

Object of the paragraph.-It will be observed that this paragraph applies only where a patient is found by a special practitioner to be suffering from a venereal disease, and gives to him information as to a person from whom he suspects that the disease was contracted. In regard to such information the object of the paragraph is threefold : (1) to prevent false statements, (2) to protect the person giving it in good faith from being exposed to the risk of an action for libel or slander, (3) to prevent the unauthorized disclosure of such information by the special practitioner. The paragraph applies to all patients in the circumstances stated, not merely to patients who attend voluntarily or subject to compulsion, but it applies only to communications made to a special practitioner by the patient. It does not apply to communications made by a patient to a doctor, e.g. his own family doctor or a general practitioner whom he consults, unless that doctor happens to be a special practitioner as defined in paragraph (7).

The general effect of the paragraph is intended to be stated in the official notes to Form 1 of the prescribed forms, to which the special practitioner is directed to draw the patient's attention before seeking detailed information as to the source of infection. In the following notes the position is gone into in rather more detail.

False statements.- Regulation 82 (2) of the Defence (General) Regulations, 1939, which is applied to information thus given, provides that if, in furnishing any information for the purposes of any of the Defence (General) Regulations any person makes any statement which he knows to be false in a material particular, or recklessly makes any statement which is false in a material particular, he is guilty of an offence against that Regulation. The maximum penalties incurred on summary conviction are three months' imprisonment, or a fine of $£ 100$, or both imprisonment and fine (see Regulation 92 of the Defence (General) Regulations, 1939).

Defamation.-In the House of Commons debate on December 15th, 1942, Dr. Russell Thomas asked the Minister of Health the following question. " "Suppose information has been given and the man or woman is found to be innocent. What remedy has such person against the informer? In law, I believe, the person would have remedies. A woman could take action for damages for slander 
without proof of special damage if allegations were made about her chastity, or if she is alleged to have an infectious disease-she has her two remedies. What remedy does she have under this Regulation?" As this question (Col. 1883, Official Report) went unanswered, it was repeated at the very end of the debate (Col. 1886, Official Report), Dr. Russell Thomas observing that such persons wrongly informed against have remedies, and can claim damages, under the law at present. The Minister of Health then replied, "My hon. Friend has got it completely wrong. All that they (presumably referring to the person suspected of being the source of infection) are asked to do is to come for examination in complete secrecy. There is no public discussion. If the Medical Officer of Health, or the local authority which would carry out the provisions of the Regulation, has reason to believe there has been malice, very heavy penalties are provided under the Defence Regulations.",

This is scarcely a reply to the question put. It is true that, under paragraph 6 (a), referred to above, a person knowingly making a false statement, or recklessly making a statement which is false in a material particular, is liable to prosecution. But what Dr. Russell Thomas was asking about was the effect of the Regulation on ordinary actions for damages for defamation.

The position as to this was not dealt with by the Minister and appears to be as follows.

It is clear law that for A to publish of B that he or she, A, has contracted venereal disease from him or her is defamatory. If written, it is a libel ; if spoken, it is a slander of that serious kind in which it is not necessary for the plaintiff to prove that he has suffered actual damage in order to be able to succeed in the action. There might be circumstances in which such a statement was privileged, and it would be a defence for A to prove the truth of the statement. Prima facie, however, such a statement is actionable.

Paragraph (6) (b) modifies this to a limited, but nevertheless important, extent. If such an accusation is made by a patient to a special practitioner who has found him or her to be suffering from a venereal disease, the information so given is "deemed to have been communicated in pursuance of a statutory duty," so far as the law of defamation is concerned. The effect of this is that the statement is privileged. Not absolutely privileged, but privileged to this extent, that no action for damages will lie merely because it turns out that the statement is untrue. The plaintiff must, in order to succeed, prove that the statement was made maliciously, that is, not made bona fide with a belief in its truth.

One of the main difficulties in cases in which the plaintiff's success in an action for defamation depends upon the defendant having acted maliciously is that of proof, and the onus rests on the plaintıff.

Suppose, for example, A tells the special practitioner that he suspects B as being the source of infection. In response to questions he further states a date-or several dates-when he has had sexual relations with $B$. These dates are such that $B$ could quite well be the source of infection, and the special practitioner duly sends Form 1 to the appropriate Medical Officer of Health. Of course nothing can happen unless another notice has also reached that Medical Officer. But if it has, and if $B$ is eventually examined and found not to be suffering from a venereal disease, B would have a very slight chance of success in any action for slander against $A$ unless it were shown that there had not in fact been sexual relations between the parties on the dates alleged. Any misstatements of fact of that kind would, of course, destroy the privilege. So, too, if the patient had concealed from the special practitioner other possible sources of infection, that would appear to prevent the statement being made in good faith.

What, it may be asked, would be the position of the special practitioner or Medical Officer of Health should actions of this kind be brought? This is dealt with below.

Position of special practitioner in regard to information given by patient.-Subparagraph $(c)$ provides that information given to the special practitioner as to the suspected source of infection shall be deemed, for the purposes of Regulation 84 
of the Defence (General) Regulations, 1939, to have been obtained by him by virtue of Regulation 33B. The effect of this, having regard to Regulation 84 , is that he must not "otherwise than in connection with the execution of these Regulations (i.e. the Defence (General) Regulations, 1939, of which Regulation 33B forms part), or of an order, rule or bye-law made under the Regulations, disclose that information except with permission granted by or on behalf of, a Minister of the Crown."

Any unauthorized disclosure would, in fact, be an offence under the Regulations for which the special practitioner could be prosecuted. That is some protection for the person named as the source of infection.

But does this justify the statement made in Note 1 to Form 1, to which the Minister has directed that the patient's attention must be called before he is asked to give detailed information as to the suspected source of infection? That depends upon what the patient takes these words to mean. If he understands thereby that what he tells the special practitioner will not be communicated further, that is wrong. Indeed, the primary obligation imposed by the Regulation-the very thing on which its whole operation depends-is the legal obligation which is imposed on the special practitioner to pass on the information to the appropriate Medical Officer of Health.

Of course, in so passing on the information the special practitioner is himself acting in pursuance of a statutory duty, and is thus himself protected, while the Medical Officer of Health who receives it obtains it by virtue of the Defence (General) Regulations, 1939, and is thus, by virtue of Regulation 84, under the obligation not to disclose it--except as permitted by that Regulation. Even so, there may be a further communication by him in connexion with the execution of the Regulations, and the steps that he takes may subsequently lead to a prosecution of the person whom the patient names. It may be doubted whether most patients would consider that this was treating the information they gave as " strictly confidential." This matter has not been gone into here by way of adverse criticism, but merely because it is well to get the facts clear. The special practitioner discharges the legal obligation imposed on him by merely drawing the patient's attention to the Notes on Form 1. But the doctor also has duties as a doctor in regard to his patient. The patient may well ask the special practitioner what is the real meaning of the notes. He may ask whether the doctor " will tell anyone." If the doctor then says "What you tell me will be treated as strictly confidential,', he no doubt complies with the law, i.e. with the Minister's direction. Can it, however, be said that he is not misleading the patient ? A question of medical practice is involved here, but it may be pointed out that there is nothing to prevent a doctor from amplifying the information given in the notes to the form, and explaining what is the real position.

\section{Privilege in regard to court proceedings}

Cases which may arise under the Regulation.-There is not space in this commentary to consider in any detail the vexed, and still unsettled, question of medical privilege in regard to proceedings in Court. Possibly it may be dealt with in a later article, but a few words will not be out of place by way of reminder.

The court proceedings which may obviously arise out of this Regulation-and this is not an exhaustive list-are as follows.

(1) Civil action for libel or slander by a person named as the source of infection, but who is not infected. . It will be remembered that for a patient to allege that he has contracted a venereal disease from a particular person normally involves two allegations. First, the fact of sexual intercourse having taken place ; secondly, that the person in question was suffering from a venereal disease and communicated it to the patient. Both these allegations are defamatory ;

(2) Criminal prosecution for libel, and for conspiracy to libel. For example, $A$ and $B$ having contracted a venereal disease agree that they will both name $X$ as the source of infection, neither, or one only of them, having had sexual relations 
with $\mathrm{X}$, or neither or one only of them having any cause to suspect $\mathrm{X}, \mathrm{X}$ being actually free from disease ;

(3) Criminal prosecution of patient under Regulations 33B (6) (a) and 82 for making a statement which he knows to be false in a material particular, or for recklessly making a statement which is false in a material particular ;

(4) Criminal prosecution of special practitioner for wrongfully disclosing information received from patient, contrary to Regulations 33B (6) (c) and 84 ;

(5) Criminal prosecution of Medical Officer of Health, or other person who obtains information by virtue of Regulation 33B which has been communicated to the special practitioner, for wrongfully disclosing such information contrary to Regulation 84 ;

(6) Criminal prosecution of a contact for failing to attend and submit for examination, or for failure to comply with a Treatment Notice, or with directions given pursuant thereto ;

(7) Criminal prosecution of a special practitioner for failure to carry out the duties imposed upon him by the Regulation; for example, failure to send notice to the Medical Officer of Health when a patient has named a person as the suspected source of infection.

All these court proceedings require the proof of certain facts by evidence. Not all of these involve medical evidence, or raise questions of medical privilege. For example, if $\mathrm{A}$ is prosecuted for not complying with a notice to attend and submit to examination (Form 2 ) the only question is whether the notice is formally correct, whether it has been duly served, and whether it has in fact been complied with. No difficulty arises in most cases. Yet, even in such an apparently simple case, there may be difficulty. The defence, since many persons have the same name, and the identification of a person in the notice sent by the special practitioner to the Medical Officer of Health is not necessarily by name (see Form 1), may be that the person on whom the notice to attend for examination is served is not in fact the person named in the notices sent to the Medical Officer of Health. Defending such a person-it may be a girl who is a virgin, and has never had sexual relations with anyone, and who has her own medical evidence to prove this-one would naturally use every means that the law allows in order to obtain information as to what was said by the patients who gave information to the special practitioner, and what he put on his notice. Such cases should not, of course, arise, but lawyers with an extensive experience of queer cases can have no confidence that mistakes will be wholly avoided, quite apart from malice. They are also aware that malicious allegations are more numerous than is commonly supposed. Obviously, in the proceedings numbered (1) to (4) and (7), the question of how far a special practitioner can be compelled to disclose the information which he has been given, or how far he is at liberty to do so, may arise in a very acute form.

The point was raised by Lord Dawson in the House of Lords Debate on December 8th, 1942 (Official Report, Cols. 455-456). He said that he would like to refer to the matter of "preserving secrecy, and not only preserving secrecy, but preserving the belief of people in secrecy,' observing that that was one objection to compulsory notification. He also observed that "since secrecy was promised some years ago in connection with venereal diseases, there have been, I think, three occasions on which secrecy has been thrust aside in a Court of Justice " and observed that " it is worth our while to consider soberly the general question of medical privilege which is here involved.' Lord Atkin (Official Report, Col. 459), instanced the case of a man who had gone for treatment to a clinic under the belief, as stated in printed notices, that secrecy was guaranteed. Then in a matrimonial case the doctor was told by the Judge that there was no privilege, and that he must divulge from what the patient was suffering. "To my mind," said Lord Atkin, " medical privilege in circumstances of this kind is a national necessity, because people will avoid going to doctors if they know that a doctor can be compelled to disclose the information in his possession.",

Lord Snell, in replying on behalf of the Government, did not touch on the question of privilege at all. 


\section{REGULATION 33B}

The Common Law position.-In Halsbury's Laws of England (2nd Edn.) Vol. 22, p. 322 the general position is thus stated. "A medical practitioner may be asked to disclose on oath information which came to him through his professional relationship with a patient, and, if the question is not inadmissible on other grounds he may be committed to prison if he refuses to answer.'

That is undoubtedly a correct statement of the inveterate rule of English law. How it is applied is illustrated in the case of Garner v. Garner (1920), 36 T.L.R. 196. A medical practitioner who, in the course of treating a patient under the national scheme for the treatment of venereal diseases, ascertained that the patient was suffering from such a disease was compelled to give evidence in Court to that effect, although the statutory regulations applying to the scheme enjoin absolute secrecy on the medical practitioner.

It is interesting to note the actual words of the regulation as to secrecy which were handed to the Judge in the above case. These Regulations are the Public Health (Venereal Diseases) Regulations, 1916, S.R. \& O. 1916 No. 467. Article 2 (2) of these is very wide, and is in the following terms : "All information obtained in regard to any person treated under a scheme approved in pursuance of this Article shall be treated as confidential.'. Would not a patient shown that regulation think that what the doctor discovered was immune from disclosure? It must be rememberd that this regulation is still in force in regard to persons treated under approved schemes.

It does not, of course, follow that a medical practifioner who refused to answer any such questions would be committed to prison for contempt. In Kitson v. Playfair (1896), the Times, March 28th, Mr. Justice Hawkins said that "I can quite understand a case, especially in a civil case, when a doctor is quite justified in refusing to divulge questions of professional secrecy. . . . The Judge might in some cases refuse to commit a medical man for contempt in refusing to reveal confidences. Every case must be governed by the particular circumstances, and the ruling of the Judge must be the test." Lord Dawson referred to the possibility of a refusal to answer questions in the recent House of Lords debate, and said that "if only a medical man would put his two feet on the ground and say 'I won't do it,' it would bring an end to the whole business." 'But whether a determined stand by a doctor did or did not result in a change being made in the law, the general rule is at present as stated above, namely, that there is no privilege which entitles a medical practitioner to refuse to disclose what passes between himself and his patient if the questions he is asked are otherwise (that is, as being relevant, not hearsay, etc.) admissible.

Effect of Regulation $33 B$ in regard to privilege.-It cannot be too strongly emphasized that the combined effect of Regulation 33B (6) (c) and Regulation 84 is not to create a new kind of general medical privilege, but to impose an obligation of a special limited kind upon the special practitioner. This obligation is that he must not, in general, disclose what a patient whom he has found to be suffering from a venereal disease tells him as to a person from whom the patient suspects he contracted that disease. He may, however, make such disclosure (1) in connection with the execution of the Regulations or of any order, rule or bye-law made under the Regulations, and (2) with permission granted by or on behalf of a Minister of the Crown.

It must be observed that the prohibition against the disclosure of information, when it applies at all, applies whether or not the special practitioner has in fact acted on the information by sending in a notice to the Medical Officer of Health.

Prima facie it would no doubt appear that, while there is nothing in the Regulations to protect the special practitioner against being compelled to disclose in Court what he has been told where the proceedings are in connection with the enforcement of the Regulation, he could not be compelled to make disclosure in an action of libel or slander, etc. which has nothing to do with the execution of the Regulations. But is there even this last, and very limited, protection? Under the 1916 Regulations the words were " all information . . . shall be regarded 


\section{THE BRITISH JOURNAL OF VENEREAL DISEASES}

as confidential." The present words are " no person shall disclose that information." What is the difference ? I do not think there is any difference in intention, but I think that a modern decision of the House of Lords justifies the proposition that the special practitioner may lawfully refuse to make disclosure, even to a Court which he attends on subpoena to give evidence, except in those two classes of cases in which Regulation 84 permits him to make disclosure. For, except in those cases, he is subject to a penalty if he makes disclosure. It would be a criminal offence, and, as Lord Wright said, in the case referred to, "a Judge cannot compel a man to commit a criminal offence." This case, Rowell v. Pratt (1938) A.C. 101 ; (1937) 3 All E.R. 660, turned on the construction to be placed on s. 17 (2) of the Agricultural Marketing Act, 1931. That section provides that " any person who discloses any information obtained by him in the exercise of any power conferred on him by or under the provisions of this Act ". . . shall be guilty of an offence. There are certain exceptions not material here, although they may have influenced the construction put upon the statute. The House of Lords held that an official of the Potato Marketing Board could not be compelled by a court of law to produce a return containing information given pursuant to the Act.

Each statute or statutory rule has, of course, to be independently construed having regard to its entire context, but it appears to me that this case justifies a special practitioner in refusing to answer any questions in Court regarding information given by a patient as to the suspected source of infection unless the proceedings are proceedings for the enforcement of the Regulation, since in that case they are " in connection with the execution of the Regulations," and disclosure for this purpose is not prohibited by Regulation 84. If permission is given by the Minister the special practitioner not only may, but must, give evidence if required.

Except to this limited extent there is no privilege.

Medical Officers of Health and disclosure.-There is a very important difference between special practitioners and the Medical Officer of Health in regard to the information they receive. In the case of the special practitioner it is only information received from his patient as to the suspected source of infection that it is an offence to disclose, and which he may, to the limited extent noted above, refuse to disclose.

In the case of a Medical Officer of Health, however (and this applies to any assistants, etc. in his department too), all his information is information received by virtue of Regulation 33B and therefore its disclosure is prohibited by Regulation 84 , except in so far as that regulation otherwise provides. $\mathrm{He}$ is, for example, told on the "Notice of Suspected Source of Infection", (Form 1) the name, address and disease of the patient who has given the information to the special practitioner. He, therefore, is, although the special practitioner is not, prohibited from disclosing this.

Apart, however, from the fact that the prohibition against disclosure is wider in scope in the case of the Medical Officer of Health his position in regard to refusing to give evidence appears to be the same as that stated above, namely that he may so refuse only in those cases in which the effect of Regulation 84 is to prohibit him from making disclosure.

(7) The Minister of Health may make rules for prescribing anything required to be prescribed under this Regulation, and may give such general or special directions as he thinks fit as to the performance by Medical Officers of Health and by special practitioners of the duties required of them, respectively, for the purposes of this Regulation; and such directions may in particular make provision-

(a) for the issue, to contacts and to patients by whom such information as is mentioned in paragraph (6) of this Regulation is given, of instructions approved by the Minister explaining the effect of all or any of the provisions of this Regulation ;

(b) for requiring particulars of any transfer notices to be communicated by and to the medical officers of health and special practitioners concerned; and

(c) for requiring special practitioners to furnish free of charge any certificates required for the purposes of this Regulation. 


\section{REGULATION 33B}

\section{Note to paragraph (7)}

It is under the power conferred by this paragraph that the Minister of Health has made Rules prescribing Forms 1 to 3 for use in England and Scotland respectively (S.R. \& O. 1942 No. 2356 and S.R. \& O. 1943 No. 22) and has issued the Directions to Special Practitioners dated January 8th, 1943, which also prescribe for use Forms 4 and 5, and the Directions to Medical Officers of Health, also dated January 8th, 1943. These have all been dealt with above in the notes to the particular paragraphs of the Regulation which they concern.

(8) In this Regulation the following expressions have the meanings hereby respectively assigned to them, that is to say-

' clearance certificate' means, in relation to any contact, a certificate in writing given by a special practitioner certifying that the contact is not, at the date of the certificate, suffering from a venereal disease in a communicable form ;

'prescribed ' means prescribed by rules made under this Regulation ;

'special practitioner' means a registered medical practitioner who is qualified under the Local Government (Qualification of Medical Officers and Health Visitors) Regulations, 1930, to be a venereal diseases officer, or who is or has been a venereal diseases officer by virtue of a dispensation given by the Minister under those Regulations, or who is a medical officer of any of His Majesty's forces employed for the time being as a specialist in venereal diseases, or who is for the time being designated by the Minister of Health for the purposes of this Regulation;

' treatment' includes any periodical or other medical examination ;

'venereal disease ' means gonorrhoea, syphilis or soft chancre.

\section{Notes to paragraph $(8)$}

Clearance certificate.-The form the certificate is to take has now been prescribed in the direction to special practitioners dated January 8th, 1943, and is given in the notes to paragraph (3).

Special practitioner.- It will be observed that the definition of a special practitioner covers four classes of registered medical practitioners.

(1) Those who are qualified under the Local Government (Qualification of Medical Officers and Health Visitors) Regulations, 1930, S.R. and O. 1930, No. 69, to be venereal diseases officers ;

(2) Those who are or have been venereal diseases officers by virtue of a dispensation given by the Minister under these regulations;

(3) Medical Officers of any of His Majesty's forces for the time being employed as specialists in venereal diseases. This will include medical officers of the Dominions and of the Women's Forces ;

(4) Persons for the time being designated as special practitioners for the purpose of these Regulations.

Except in the case of the last class there is not any question of a special appointment for the purpose of the Regulations. It is stated in the Ministry of Health Circular to Medical Officers dated January 8th, 1943, that any practitioner not falling within the first three classes above who wishes to be designated as a special practitioner for the purpose of Regulation 33B should apply to the Medical Officer of Health of the County or County Borough in which he practises, giving particulars of his experience in the treatment of venereal diseases. The application will then be sent, together with the Medical Officer of Health's recommendation, to the Secretary, Ministry of Health, Whitehall, London, S.W.1.

There is a different definition of special practitioner in regard to both Scotland and Northern Ireland (see paragraphs 9 and 10, below).

(9) This Regulation shall, in its application to Scotland, have effect subject to the following modifications:-

(a) for any reference to the Minister of Health there shall be substituted a reference to the Secretary of State ;

(b) any reference to a county shall, in the case of counties combined under the Local Government (Scotland) Act, 1929, be construed as a reference to the 


\section{THE BRITISH JOURNAL OF VENEREAL DISEASES}

combined county, for any reference to a county borough there shall be substituted a reference to a large burgh within the meaning of the said Act, and any burgh other than a large burgh shall be deemed to be included in the county in which it is situated ;

(c) for the definition of 'special practitioner' there shall be substituted the following definition :-

'special practitioner' means a registered medical practitioner who provides treatment in accordance with the venereal diseases scheme of a local authority approved by the Secretary of State, or who is a medical officer of any of His Majesty's forces employed for the time being as a specialist in venereal diseases, or who is for the time being designated by the Secretary of State for the purposes of this Regulation.

Notes to paragraph (9)

Application of Regulation to Scotland.-The only differences in the application of the Regulation to Scotland are (1) that the Secretary of State discharges in Scotland the functions which in England are discharged by the Minister of Health, (2) that there is the usual modification necessitated by the difference in local government areas, and (3) that there is a different definition of a special practitioner. In the case of a medical practitioner wishing to be designated as a special practitioner for the purpose of Regulation 33B in Scotland under the concluding words of this paragraph, his application should be forwarded to the Secretary of State for Scotland, instead of to the Minister of Health.

(10) This Regulation shall, in its application to Northern Ireland, have effect subject to the following modifications:-

(a) for any reference to the Minister of Health there shall be substituted a reference to the Ministry of Home Affairs for Northern Ireland;

(b) any reference to the Medical Officer of Health shall be construed, in relation to a county borough, as a reference to the medical superintendent officer of health, and, in relation to a county not being a county borough, as a reference to such registered medical practitioner as may be designated for the purposes of this Regulation by the Ministry of Home Affairs for Northern Ireland as the Medical Officer of Health for the county;

(c) for the definition of 'special practitioner' there shall be substituted the following definition:-

" "special practitioner" means a registered medical practitioner who is in clinical charge of a treatment centre established by, or in receipt of a grant from, a local authority, for the diagnosis and treatment of venereal diseases, or who is a medical officer of any of His Majesty's forces employed for the time being as a specialist in venereal diseases, or who is for the time being designated by the Ministry of Home Affairs for Northern Ireland as a special practitioner for the purposes of this Regulation.'

Notes to paragraph (10)

Application of Regulation to Northern Ireland.-Regulation 33B did not originally apply to Northern Ireland, the original paragraph (10) having provided that it should not do so. The new paragraph (10), printed above, was substituted as from February 10th, 1943, by S.R. \& O. 1943 No. 193, and provides that the Regulation shall apply to Northern Ireland subject to the modifications therein specified. The only modifications are: (1) the Ministry of Home Affairs for Northern Ireland discharges the functions there which the Minister of Health discharges in England, and (2) there is a necessary modification in regard to Medical Officers of Health. The Medical Superintendent Officer of Health discharges in a County Borough the functions which in an English County Borough would be discharged by the Medical Officer of Health, and in other counties the duties will be discharged by such registered medical practitioner as may be designated for the purpose of the Regulation by the Ministry of Home Affairs for Northern Ireland as the Medical Officer of Health for the County, and (3) there is a different definition of a special practitioner.

The institution of proceedings for an offence against Regulation 33B.-The institution of legal proceedings, except in Scotland, for offences against any of the Defence (General) Regulations, 1939, is governed by Regulation 93, paragraph (1) 
of which provides that such proceedings may, unless the particular regulation otherwise provides, only be instituted either (1) by a constable, or (2) by or with the consent of the Director of Public Prosecutions, or (3) in the case of proceedings for an offence against any provision of the Regulations specified in Schedule III, in the manner therein indicated.

In practice, so far as Regulation 33B is concerned it is under this last heading that proceedings will mostly be instituted, for an addition was made to that Schedule in regard to Regulation 33B, which (in its present form, as substituted by S.R. \& O. 1943 No. 193 from February 10th, 1943) provides that proceedings under the Regulation arising out of a notice served by a Medical Officer of Health (or Medical Superintendent Officer of Health appointed or designated for any County or County Borough) may be instituted by or on behalf of the Council of the County or County Borough.

This covers cases in which it is desired to proceed against a person for failing to comply with a notice to submit to examination; etc. It does not, however, cover cases in which the alleged offence is, for example, the wrongful disclosure of information by a special practitioner or by the Medical Officer of Health, or the making of false statements by a patient as to the suspected source of infection. In such cases, that is in all cases not covered by the words of Schedule III referred to above, the proceedings can be instituted only by a constable, or by or with the consent of the Director of Public Prosecutions.

What is probably one of the first prosecutions under the Regulation is noted in the Justice of the Peace for March 20th, 1943, on p. 139. This was on March 4th, 1943. The defendant, who was charged with failing to comply with a direction requiring her to be examined, failed to appear, and a warrant was issued for her arrest. Her attendance being thus secured, she pleaded guilty and was sentenced to two months' imprisonment. It will obviously be desirable in all prosecutions under the Regulation to secure the personal attendance of the accused in this way when the person charged does not appear voluntarily to answer to the summons.

Where the council is the appropriate prosecuting authority.-In those cases in which the council of the County or County Borough is the appropriate prosecuting authority the question whether or not any proceedings are to be instituted in any individual case will be a matter for the council. The Ministry of Health Circular dated January 8th, 1943, observes that the Medical Officer of Health will no doubt consult the council's legal adviser before any action to this end is taken. Obviously, in such cases, there must be a certain disclosure by the Medical Officer of Health of the information he has received, but as this is made in connexion with the execution of Regulation 33B the disclosure is permissible-but the legal adviser, or a member of the Council, who so receives this confidential information is under the like duty not to disclose it, and a breach of this duty would render him liable to prosecution.

Duties of Medical Officers of Health in regard to records.-No obligation as to keeping records is imposed by Regulation 33B, and in the circular letter dated January 8th, 1943, sent to Medical Officers of Health it is stated that it is not thought necessary to require local authorities to furnish any regular returns. Medical Officers of Health are, however, informed in the same letter that the Chief Medical Officer of the Ministry of Health will be glad to receive at the end of each quarter during the first year of the operation of the Regulation (which came into force on November 5th, 1942) a note indicating (1) the number of contacts in respect of whom notices have been served by the Medical Officer, and (2) the number in respect of whom either (a) informal or (b) formal action has been taken, and (3) the results of such action.

\section{FINAL OBSERVATIONS}

Although not originating from the interpretation of Regulation 33B, there are one or two points arising out of the discussions which attended the introduction of the Regulation of which it seems worth while to take note. 


\section{Medical and moral issues}

In the first place there seemed both in the House of Lords and in the House of Commons a certain element of confusion-perhaps several different elements of confusion-in regard to whether the treatment of venereal diseases was a medical or a moral issue. Since those debates the Archbishop of Canterbury and other leaders have declared that it is essentially a moral issue. If, however, Regulation $33 \mathrm{~B}$ is to be regarded - and we have seen that this is the official view-as a war-time regulation which is introduced because the nation simply cannot afford the loss of man-power caused by the incidence of the diseases, obviously the only approach can be a purely medical one. On the other hand, looking at the matter in its wider aspects and having regard to the fact that quite innocent people may be and frequently are infected, one may still prefer the way in which the matter was put in the House of Commons by Mr. Driberg, when he said that "It is primarily a medical and not a moral issue, although it has certain important social implications." Nor is it out of place to remember the timely observation of Lord Dawson in the House of Lords referring to what happened during the last war. He observed that when the difficulties which were felt concerning the establishment of " preventive clinics" were referred to Rome in order to get the official view of the Roman Church stated, after a sufficient consideration of the question there was given out a brief edict that because a man imperils his immortal soul that is no reason why we should not do the best we can for his mortal body (House of Lords Official Report, December 8th, 1942, Col. 453).

\section{Further steps}

In the second place it is surprising, this being regarded as a war-time measure, that more has not been done. We are well on in the fourth year of war. How much has been accomplished so far ? The Minister of Health pointed out that there are two hundred and forty-nine treatment centres in Great Britain, threequarters of which are at hospitals, yet of these two hundred and forty-nine centres only eighteen have been provided since the war began, and there are only five more centres which are on the point of opening. During all this time it has been known officially that the rate of new infections was increasing and is still increasing. At the beginning of 1940 the Minister of Health issued circular No. 1956 to local authorities. This told local authorities precisely what they might expect as a result of the dispersal of the population, the creation of munition works and camps, and the other changes brought about by the war. Nothing much was done by the local authorities, and the Ministry seemed to have been content with the position until recently. Yet it is obvious that whatever regulations are passed it will prove impossible to deal effectively with venereal diseases unless specialists in them are available to administer treatment in every area. In present circumstances it is fairly obvious that the whole of the effort to deal with the diseases should be financed entirely on a national basis.

\section{Value of comparison with statistics from other countries}

In the third place it was surprising that more information was not given on behalf of the Government in the debates both in the House of Lords and in the House of Commons, as to the experience of other countries, and particularly the experience of the Dominions and possessions of the Crown. Lord Snell in the House of Lords contented himself with the observation that figures given for Sweden, with a population of six and a half millions, were hardly comparable with figures which might be given in regard to New York. The-Minister of Health in the House of Commons also referred to the figures which had been given in regard to Sweden, and pointed out certain reasons why they were not comparable with the English figures. That is not very helpful ; so far as it appears from the Government statement, a proper estimate may or may not have been made of the experience of the many different countries in which there has been legislation in regard to the venereal diseases for a considerable number of years, 


\section{RECOMMENDATIONS ON THE TREATMENT OF MERCHANT SEAMEN}

along lines different from those which have been adopted in Great Britain. Surely the House of Commons ought to have been informed by the Minister of Health of what comparative information was available in regard to the different schemes ! No facts were given in regard to the treatment of the diseases in the Dominions. There has, for example, been a new Venereal Diseases Prevention Act passed in Ontario, which is much wider in scope than anything which has been attempted here (see the explanation on pp. 486-489 of the Canadian Public Health Journal, October, 1942). There must also be a considerable volume of statistical information available in regard to the many states of the United States of America which have adopted special legislation. It might indeed, have been worth while to have made public in the debate the experience gained even in Great Britain during the war of 1914-18. Has it, for example, been established whether Regulation 40D of the Defence of the Realm Regulations passed during that war really assisted in lessening the number of infections? Medical practitioners will probably feel that more purpose would be served by all available information being collected and made readily accessible, than by debates being conducted in the somewhat heated way in which the House of Commons debate was in part conducted, without there being adequate information to support most of the allegations which were made.

From this point of view it does seem unfortunate that the Ministry has not seen fit to require local authorities to furnish regular returns in such a form that the effect of the present regulation could be better observed.

\section{RECOMMENDATIONS OF THE MINISTRY OF HEALTH ON THE TREATMENT OF MERCHANT SEAMEN}

Issued in March, 1943.

The following recommendations apply only to early cases.

\section{A. Gonorrhoea}

(1) When the disease is discovered whilst the seaman is ashore, it is assumed that the diagnosis will be established by laboratory tests ; that the patient will be treated with 4 to 5 grammes sulphathiazole or sulphadiazine daily for four to seven days, this treatment being supplemented by urethral irrigations ; and that if he responds normally to this treatment, he will be tested for cure by well recognized methods.

On this assumption, if no sign of persistence of the infection is discovered seven days after suspension of treatment, the patient should be discharged to full duty.

It is important, however, that in his own interest the patient be re-examined at the end of about three months when he should also be tested for syphilis.

(2) If the disease is discovered whilst the seaman is at sea in a ship not carrying a surgeon, he should be treated with sulphathiazole or with sulphadiazine by a ship's officer as follows :-Six tablets of 0.5 gramme to be taken twice daily for a maximum of five days. Each dose to be crushed up by the teeth and swallowed with a tumblerful of water.

Throughout this treatment and for two days thereafter the patient should drink five pints of water daily.

On arrival at a port provided with a V.D. treatment centre, he should be directed to attend at a treatment centre to be tested for cure, the tests including one for syphilis, and a final test of cure with a test for syphilis should be carried out in a treatment centre not less than three months after completion of the treatment.

(3) If the disease is discovered when the seaman is at sea in a ship carrying a surgeon, the procedure should be like that set out in (1) or in (2) according to the facilities available on the ship for microscopical examination and for treatment as 